\title{
Concomitant Plasmodium falciparum and intestinal helminth infections in a rural community of southern Côte d'lvoire
}

\author{
Richard B Yapi ${ }^{1,2^{*}}$, Eveline Hürlimann ${ }^{3,4}$, Kigbafori D Silué ${ }^{1,2}$, Clarisse A Houngbedji ${ }^{1,5}$, Chammartin Frédérigue ${ }^{3,4}$, \\ Penelope Vounatsou ${ }^{3,4}$, Jürg Utzinger ${ }^{3,4}$, Eliezer K N'Goran ${ }^{1,2}$, Giovanna Raso ${ }^{1,3}$
}

From Challenges in malaria research

Basel, Switzerland. 10-12 October 2012

\section{Background}

Despite efforts to control the disease, malaria is still threatening the life of millions of people in sub-Saharan Africa [1]. In addition the distribution of malaria often overlaps in space with so called neglected tropical diseases (NTDs). People in endemic areas can therefore host more than one parasite species infection at the same time, hence making polyparasitism a common phenomenon [2-4]. The consequences of these diseases are manifold and can include impairment of cognitive development and anemia, school aged-children and pregnant women representing the most vulnerable groups with particular risk of morbidity [4-6]. In Côte d'lvoire, these diseases are widely prevalent but vary in their spatial distribution and present different patterns of associations. Risk factors such as distance to water bodies and socio-economic status have been identified among the underlying causes for this heterogeneity $[7,8]$ As a result of this heterogenous occurrence of multi-parasite infections related morbidity and burden due to polyparasitism will vary as well between areas. For control activities decision making usually takes place at global and/or national level but for integrated, cost-effective and sustainable control efforts better understanding of co-infection dynamics at different spatial scales are urgently needed. The main goal of this study was therefore to describe the pattern of concomitant infections with Plasmodium and intestinal helminths in a rural setting in southern Côte d'lvoire.

\section{Method}

A cross-sectional study was conducted in a hamlet of Azaguié, named Ancien Carrefour", located $40 \mathrm{~km}$ from

'Departement Environnement et Santé, Centre Suisse de Recherches

Scientifiques, Abidjan, Côte d'Ivoire, 01 BP 1303 Abidjan 01

Full list of author information is available at the end of the article
Abidjan, in September 2011. Blood and faecal specimens were collected to identify Plasmodium spp, Schistosoma mansoni, soil-transmitted helminths (hookworm, Ascaris lumbricoides, Trichuris trichiura), and intestinal protozoan infections by microscopy using standardized qualitycontrolled procedures. The study involved 413 persons from 85 households. Data analysis was done using logistic and multinomial regression models taking into account household effects.

\section{Results}

Plasmodium falciparum overall prevalence was $60.53 \%$ (Table 1), which means a parasitemic index (PI) of 57.55\% that characterises a hyper endemic malaria area. Predominant NTD parasites were Schistosoma mansoni (27.36\%) and hookworm ((31.23\%) (Table 1). These parasites overlapped with $P$. falciparum. The co-infection prevalences of P. falciparum-S. mansoni and P. falciparum-hookworm were $15.98 \%$ and $18.16 \%$, respectively. Participants older than 5 years are at higher risk of co-infection compared to their younger. Multinomial analysis of co-infection of P. falciparum-S. mansoni (Table 2) reflected no significant association of age and sex to the co-infection risk. However, age was negatively related to the $P$. falciparum monoinfection risk, while female and age were negatively associated to the $S$. mansoni mono-infection risk. Multinomial analysis of co-infection of P.falciparum-hookworm (Table 3 ) showed that female were positively associated to the co-infection risk, while female and age presented a positive association to the hookworm mono-infection risk and age presented a negative association to $P$. falciparum mono-infection risk. 
Table 1 Logistic regression for single parasite species infections regardless of any other parasite species infection, accounting for household effects

\begin{tabular}{|c|c|c|c|c|c|}
\hline Parasite & People infected (\%) & Independent variable & People infected (\%) & OR $(95 \% C l)^{a}$ & $P$-value \\
\hline \multirow[t]{7}{*}{ P. falciparum } & $250(60.53)$ & Age (years) & & & \\
\hline & & $0-5$ & $57(68.67)$ & 1 & \\
\hline & & $5-16$ & $96(82.05)$ & $2.08(1.06 ; 4.08)$ & 0.032 \\
\hline & & $>16$ & $97(45.54)$ & $0.38(0.23 ; 0.63)$ & $<0.001$ \\
\hline & & Sex & & & \\
\hline & & Female & $129(60.28)$ & 1 & \\
\hline & & Male & $121(60.80)$ & $1.03(0.68 ; 1.58)$ & 0.872 \\
\hline \multirow[t]{7}{*}{ S. mansoni } & $113(27.36)$ & Age (years) & & & \\
\hline & & $0-5$ & $1(1.20)$ & 1 & \\
\hline & & $5-16$ & $28(23.93)$ & 25.80(3.08; 173.73 & 0.001 \\
\hline & & $>16$ & $84(39.44)$ & $53.81(7.21 ; 401.50$ & $<0.001$ \\
\hline & & Sex & & & \\
\hline & & Female & $28(22.43)$ & 1 & \\
\hline & & Male & $65(32.66)$ & $1.69(1.10 ; 2.60)$ & 0.016 \\
\hline \multirow[t]{7}{*}{ Hookworm } & $129(31.23)$ & Age (years) & & & \\
\hline & & $0-5$ & $4(4.82)$ & 1 & \\
\hline & & $5-16$ & $39(33.33)$ & $9.88(3.50 ; 27.80)$ & $<0.001$ \\
\hline & & $>16$ & $86(40.38)$ & $13.21(4.06 ; 34.50)$ & $<0.001$ \\
\hline & & Sex & & & \\
\hline & & Female & $54(25.23)$ & 1 & \\
\hline & & Male & 75 (37.69) & $1.77(1.23 ; 2.54)$ & 0.002 \\
\hline
\end{tabular}

adds Ratio

Table 2 Multinomial logistic regression for $P$. falciparum and $S$. mansoni mono and co-infection with age and sex as independent variables, accounting for household effects

\begin{tabular}{|c|c|c|c|c|c|}
\hline \multirow[b]{3}{*}{ Infection } & \multicolumn{4}{|c|}{ Covariates } & \multirow[b]{3}{*}{ P-value } \\
\hline & \multicolumn{2}{|c|}{ Sex } & \multicolumn{2}{|c|}{ Age } & \\
\hline & Positive for infection (\%) & $\operatorname{RRR}(\mathrm{Cl} 95 \% \mathrm{Cl})^{\mathbf{b}}$ & P-value & $\operatorname{RRR}(\mathrm{Cl} 195 \% \mathrm{Cl})^{\mathrm{b}}$ & \\
\hline P.f mono-infection ${ }^{* *}$ & $140(33.90)$ & $1.2(0.71 ; 2.02)$ & 0.495 & $0.96(0.95 ; 0.98)$ & $<0.001$ \\
\hline S.m mono-infection** & $20(4.84)$ & $2.31(1.21 ; 4.40)$ & 0.011 & $1.01(1.00 ; 1.03)$ & 0.102 \\
\hline P.f-S.m co-infection & $35(8.47)$ & $1.77(0.91 ; 3.42)$ & 0.092 & $0.99(0.98 ; 1.01)$ & 0.421 \\
\hline
\end{tabular}

${ }^{\mathrm{b}}$ Relative risk ratio

**People infected only with this parasite

Table 3 Multinomial logistic regression for P. falciparum and Hookworm mono and co-infection with age and sex as independent variables, accounting for household effects

\begin{tabular}{|c|c|c|c|c|c|}
\hline \multirow[b]{3}{*}{ Infection } & \multicolumn{4}{|c|}{ Covariates } & \multirow[b]{3}{*}{ P-value } \\
\hline & \multicolumn{2}{|l|}{ Sex } & \multicolumn{2}{|c|}{ Age } & \\
\hline & Positive for infection (\%) & $\operatorname{RRR}(\mathrm{Cl} 95 \% \mathrm{CI})^{c}$ & P-value & $\operatorname{RRR}(\mathrm{Cl} 95 \% \mathrm{CI})^{\mathrm{c}}$ & \\
\hline P.f mono-infection** & $140(33.90)$ & $1.16(0.68 ; 1.98)$ & 0.581 & $0.97(0.95 ; 0.99)$ & $<0.001$ \\
\hline Hookworm mono-infection** & $27(6.54)$ & $2.1(1.09 ; 4.05)$ & 0.026 & $1.02(1.01 ; 1.04)$ & 0.102 \\
\hline P.f-Hookworm co-infection & $44(10.65)$ & $1.77(1.01 ; 3.09)$ & 0.045 & $0.99(0.98 ; 1.01)$ & 0.038 \\
\hline
\end{tabular}

${ }^{\mathrm{c}}$ Relative risk ratio

**People infected only with this parasite

\section{Conclusion}

This study confirms that polyparasitism is common in rural settings. However, implications of polyparasitism on morbidity and quality of life are not well understood. Further research should focus on understanding co-infection dynamics on the purpose of designing and implementing a sustainable intregreted control strategy. 


\section{Acknowledgments}

The study received financial support from Swiss National Foundation (Project No 32003B_132949/1).

\section{Author details}

'Departement Environnement et Santé, Centre Suisse de Recherches Scientifiques, Abidjan, Côte d'Ivoire, 01 BP 1303 Abidjan 01. ²Unité de Formation et de Recherches en Biosciences, Université de Cocody, Abidjan, Côte d'Ivoire, 22 PB 582 Abidjan 22. ${ }^{3}$ Department of Epidemiology and Public Health, SwissTropical and Public Health Institute, Basel, P.O 4002 Basel, Switzerland. ${ }^{4}$ University of Basel, P.O 4003 Basel, Switzerland. ${ }^{5}$ Unité de

Formation et de Recherche en Biologie de la reproduction Animale,

Université d'Abobo-Adjamé, Abidjan, Côte d'Ilvoire, 01 BP 801 Abidjan 01.

Published: 15 October 2012

\section{References}

1. World Health Organizat: World malaria report. Worl Heal Org 2010, 32.

2. Hotez PJ, Kamath A: Neglected Tropical Diseases in Sub-Saharan Africa: Review of Their Prevalence, Distribution, and Disease Burden. PLoS Negl Trop Dis 2009, 3(8):e412, doi:10.1371/journal.pntd.0000412.

3. Magda KEllis, Raso G, Li YS, Rong Z, et al: Familial aggregation of human susceptibility to co and multiple helminth infections in a population from the Poyang Lake region, China. Int I for Parasitol 2007, 37:1153-1161.

4. Brooker S, Akhwale W, Pullan R, et al: Epidemiology of PlasmodiumHelminth Co Infection in Africa: Populations at Risk, Potential Impact on Anemia, and Prospects for Combining Control. Am J Trop Med Hyg 2007, 77(Suppl 6):88-98.

5. Jardim-Botelho A, Sophia Raff $S$, et al: Intestinal helminths and cognitive performance in Brazil. Trop Med Int Hea 2008, 13(8):994-1004, doi:10.111 1/ j.1365-3156.2008.02103.

6. Pullan R, Brooker $\mathrm{S}$ : The health impact of polyparasitism in humans: are we under-estimating the burden of parasitic diseases? Parasitology 2008, 135:783-794.

7. Raso G, Utzinger J, Silué $\mathrm{KD}$, et al: Disparities in parasitic infections, perceived ill health and access to health care among poorer and less poor schoolchildren of rural Côte d'Ivoire. Trop.Med. Int Hea 2005, 10(1):42-57.

8. Muller I, Coulibaly JT, Fürst T, Knopp S, Hattendorf J, et al: Effect of Schistosomiasis and Soil-Transmitted Helminth Infections on Physical Fitness of School Children in Côte d'Ivoire. PLoS Negl Trop Dis 2011, 5(7) e1239, doi:10.1371/journal.pntd.0001239.

9. Kato-Katz, Katz N, Chaves A, Pellegrino J: A simple device for quantitative stool thick-smear technique in Schistosomiasis mansoni. Rev.Inst.Med.Trop. Sao Paulo 1972, 14:397-400.

10. Hira PR, Behbehani K: Acetone-fixed, Giemsa-stained thick blood films for the diagnosis of malaria. Ann.Trop.Med.Parasitol 1984, 78:77-79.

doi:10.1186/1475-2875-11-S1-P105

Cite this article as: Yapi et al:: Concomitant Plasmodium falciparum and intestinal helminth infections in a rural community of southern Côte d'Ivoire. Malaria Journal 2012 11(Suppl 1):P105.

\section{Submit your next manuscript to BioMed Central and take full advantage of:}

- Convenient online submission

- Thorough peer review

- No space constraints or color figure charges

- Immediate publication on acceptance

- Inclusion in PubMed, CAS, Scopus and Google Scholar

- Research which is freely available for redistribution

Submit your manuscript at www.biomedcentral.com/submit 